\title{
A computational framework for a nutrient flow representation of energy utilization by growing monogastric animals
}

\author{
Stephen Birkett* and Kees de Lange \\ Department of Animal and Poultry Science, University of Guelph, Guelph, Ontario, Canada N1G 2W1 \\ (Received 31 October 2000 - Revised 1 July 2001 - Accepted 5 July 2001)
}

\begin{abstract}
A computational framework to represent nutrient utilization for body protein and lipid accretion by growing monogastric animals is presented. Nutrient and metabolite flows, and the biochemical and biological processes which transform these, are explicitly represented. A minimal set of calibration parameters is determined to provide five degrees of freedom in the adjustment of the marginal input-output response of this nutritional process model for a particular (monogastric) animal species. These parameters reflect the energy requirements to support the main biological processes: nutrient intake, faecal and urinary excretion, and production in terms of protein and lipid accretion. Complete computational details are developed and presented for these five nutritional processes, as well as a representation of the main biochemical transformations in the metabolic processing of nutrient intake. Absolute model response is determined as the residual nutrient requirements for basal processes. This model can be used to improve the accuracy of predicting the energetic efficiency of utilizing nutrient intake, as this is affected by independent diet and metabolic effects. Model outputs may be used to generate mechanistically predicted values for the net energy of a diet at particular defined metabolic states.
\end{abstract}

Modelling: Nutrient flows: Monogastric animals

A conceptual representation of nutrient utilization for body protein and lipid accretion by animals was described in Birkett \& de Lange (2001a). In order to use this model for practical simulation and the prediction of quantitative whole animal response to a given nutrient intake a detailed computational structure is required: (1) identification of specific nutrient and metabolite flows and a time period over which these are to be averaged; (2) a flow structure to represent the pathways which these materials can follow, i.e. the interconnections between the main processes; (3) a defined input-output response for each of the nutritional processes represented, i.e. rules for determining the output nutrient flows corresponding to given input flows; (4) identification of the external input and output nutrient exchanges with the environment, i.e. nutrient intake, secreted animal products (if any), and waste flows. This present article describes a computational framework to represent protein and lipid accretion in growing monogastric animals quantitatively, based on the concepts and structure of the nutrient process model shown in Fig. 5 of Birkett \& de Lange (2001a).
Nutrient flows are averaged on a daily basis $(\mathrm{g} / \mathrm{d}$ or $\mathrm{mol} / \mathrm{d}$ ), a time period which is consistent with experimental measurement of whole animal response for growing animals. Meaningful observations of this kind are essential for developing the control rules which select between competing nutrient pathways, and for calibration of predicted and observed biological response for a particular species, i.e. input-output response and accretion of retained animal products. Nutrient intake, expressed in terms of daily DM intake, is assumed to be a known model input, with composition characterized in terms of the main nutrient classes present in typical diets fed to monogastric animals. External nutrient outputs for growing animals consist only of wastes, i.e. non-digestible material (faeces), by-products from microbial fermentation in the digestive tract (gases), and non-metabolizable material (urine).

The essence of effective model construction lies in how the details of input-output response are developed for the individual nutritional processes. The internal structure of these transformations may be expanded to any degree of detail by introducing subprocesses. Too much detail will

\footnotetext{
Abbreviations: AA, amino acid; ACA, acetyl-CoA; AS, ash; BE, basal free energy expenditure; $\mathrm{CP}$, crude protein; CFA, crude fat; e, endogenous gut losses; $\mathrm{f}$, faecal digestible; F, fermentable; FA, fatty acid; FE, energy content of FS; FS, fermentable substrate pool; GL, glucose; GY, glycerol; i, ileal digestible; Ld, retained lipid; $M$, metabolic process; $M B$, process representing metabolic transformations; NE, net energy; NSF, non-specific fat; NSN, non-specific nitrogen; $P$, production process; Pd, retained protein; ST, starch; SU, sugars; VFA, volatile fatty acid; $\mathrm{xDM}$, non-faecally digestible DM.

*Corresponding author: Dr Stephen Birkett, fax +1 519836 9873, email birketts@ wright.aps.uoguelph.ca
} 
require the estimation, often without a sound biological or physical basis, of many parameters. The apparent complexity achieved by the many degrees of freedom of such parameterizations is neither meaningful nor robust, and obscures the conceptual link with the biological process being represented. To predict response at the whole-animal level adequately and robustly demands a minimal set of critical calibration parameters to be developed. Sensitivity analysis is useful to determine which proposed subprocesses and parameters are significant, and which can be ignored. Reasonable representations of input-output structure for the main nutritional processes are discussed in the sections below.

\section{Intake process}

The intake process (Fig. 1) represents the physical ingestion of faecal digestible DM intake (fDM), and its transformation by digestion, absorption and transport to sites for metabolic utilization. DM intake $(\mathrm{g} / \mathrm{d})$ is assumed to be characterized according to the following nutrients: ash (AS), crude protein $(\mathrm{CP}=6.25 \times \mathrm{N})$, crude fat $(\mathrm{CFA})$, starch (ST), low molecular mass sugars as defined by the LuffSchoorl method (Centraal Veevoeder Bureau, 1998; SU), and remaining organic material, largely NSP. AS is used only to calculate the residual fraction NSP $=\mathrm{DM}-\mathrm{AS}-$ CP - CFA - ST - SU (e.g. Noblet et al. 1994; Bakker, 1996). CP intake is further characterized in terms of some specific (essential) amino acids (AA), and non-specific $\mathrm{N}$
(NSN), consisting of non-essential AA, i.e. any AA not explicitly represented, and other nitrogenous compounds. Composition of the CFA is assumed known with regard to selected fatty acids (FA), and non-specific fat (NSF) defined as the difference between CFA and the fat equivalent of the specified FA. (Waste) outputs from intake non-faecally digestible DM (xDM), defined by $\mathrm{xDM}=\mathrm{DM}-\mathrm{fDM}$ and $\mathrm{N}$ from fermented CP. These are output to processes $f X$ and $u X$ for faecal and urinary excretion respectively. Interactions between nutrients, such as the effect of NSP on the digestibility of other nutrients, are not represented and are regarded as model inputs related to diet characterization, if their effects are to be taken into account. An accurate representation of intake requires separate consideration of two distinct subprocesses, enzymatic digestion $(E)$ and fermentation $(F)$.

\section{Enzymatic digestion}

For digestible nutrients other than NSP, all of which is assumed to be fermented, enzymatically digestible intake can be estimated for monogastric animals as the true ileal digestible intake, i.e. based on the assumption that, for the most part, only enzymatic processes occur prior to the terminal ileum. This simplification is not entirely accurate, since fermentation does occur in the small intestine of monogastric animals (Bakker, 1996), however, since the quantity of fermented nutrients other than NSP is relatively small, the assumption is likely not significant

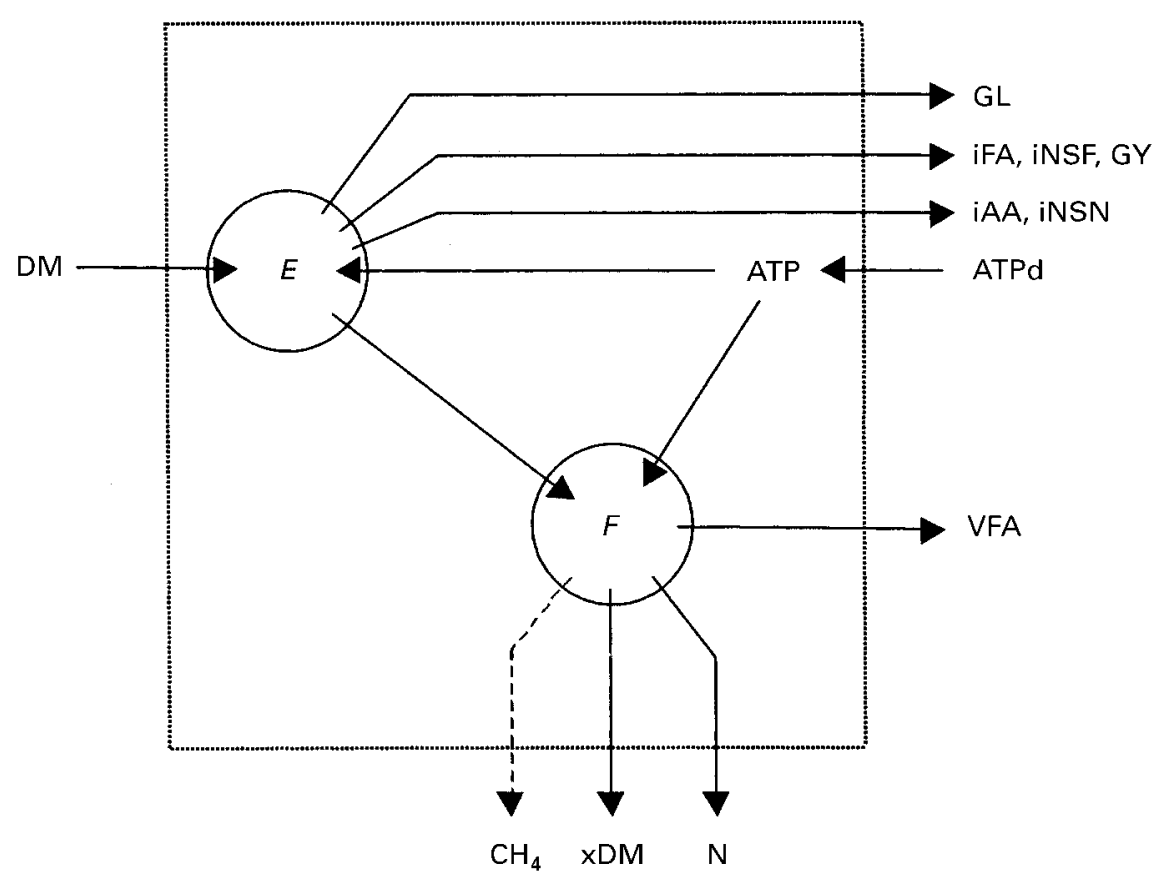

Fig. 1. Intake process I. The enzymatic digestion process $(E)$ extracts absorbed nutrients from faecal digestible DM intake (fDM): (1) glucose (GL) from starch and sugar intake; (2) fatty acids (iFA), non-specific fat (iNSF), and glycerol (GY) from fat intake; (3) essential amino acids (iAA) and non-specific nitrogen (iNSN) from protein intake. The fermentation process $(F)$ transforms remaining DM intake into absorbed volatile fatty acids (VFA), N for urinary excretion, methane loss, and non-digested faecal DM, xDM = DM-fDM. Energy required for processing fDM is derived from ATPd as a function of the fDM mass flow. Heat production is associated with intake subprocesses $E$ and $F$. 
to overall energetics. The simplified approach avoids the necessity of developing subprocesses to represent explicitly the physical and biochemical aspects of digestion, absorption and transport. Feed ingredient data in which many nutrients are already characterized in these terms is already generally available, simplifying the task of obtaining the nutrient inputs. Dietary intake must be characterized in terms of true ileal digestible (i) content of ST (iST), iCP, essential iAA, iCFA, iFA, and iSU. The intake of iNSN, consisting primarily of non-essential AA, is calculated as the iN intake (iCP/6.25) less the $\mathrm{N}$ content in the iAA. Similarly, intake of iNSF is calculated as the difference between iCFA and the fat equivalent of the specified FA in iCFA. It is assumed that $3 \mathrm{~mol}$ iFA were derived from $1 \mathrm{~mol}$ triacylglycerol, and therefore a $1 / 3 \mathrm{~mol}$ glycerol (GY) intake can be associated with each mol iFA intake.

The iST and iSU intakes contribute directly to absorbed glucose (GL). To represent the increase in molar weight from ST hydrolysis, iST is multiplied by the ST:GL ratio of molar weights (180/162), or, equivalently, by the ST:GL ratio of heats of combustion $(17 \cdot 35 / 15 \cdot 64)$. Molar weights of SU in the diet may vary, due to the monomer sugar composition and degree of polymerization. Therefore, to convert SU intake to absorbed GL, an estimated average heat of combustion for sugars is used $16.8 \mathrm{~kJ} / \mathrm{g}$ is typical of the SU component of pig diets (Birkett \& de
Lange, 2001b) multiplying iSU (g/d) by the ratio of this to the heat of combustion of GL $(15.64 \mathrm{~kJ} / \mathrm{g})$.

Metabolite outputs from $E$ consist of the molar flows of absorbed iAA, iNSN, iFA, iNSF, GY, and the combined GL flow derived from iST and iSU. Nutrient intake in fDM which is not digested enzymatically is processed by fermentation.

\section{Fermentation}

The main absorbed energy-yielding products of fermentation are volatile FA (VFA): acetic, propionic, butyric, etc. Other products are ignored. In general, an explicit representation of all the important interacting biochemical and microbial processes in the hindgut, rumen, or caecum (Fig. 2) can be complex and difficult to parameterize (e.g. Dijkstra et al. 1992). However, for monogastric animals a simplified representation of $F$ is likely to be sufficient, even though a substantial proportion of total energy from commercial diets may be derived through fermentation (Noblet et al. 1989; Bakker, 1996). In the simple model, contributions to a fermentable substrate pool (FS), derived from various sources, are converted to VFA via an energetic transformation and an estimated efficiency of transfer which takes into account energy lost as heat and methane.

The diet is characterized in terms of apparent faecal digestible nutrients fCP, fCFA, fST, fSU, and fNSP. It is

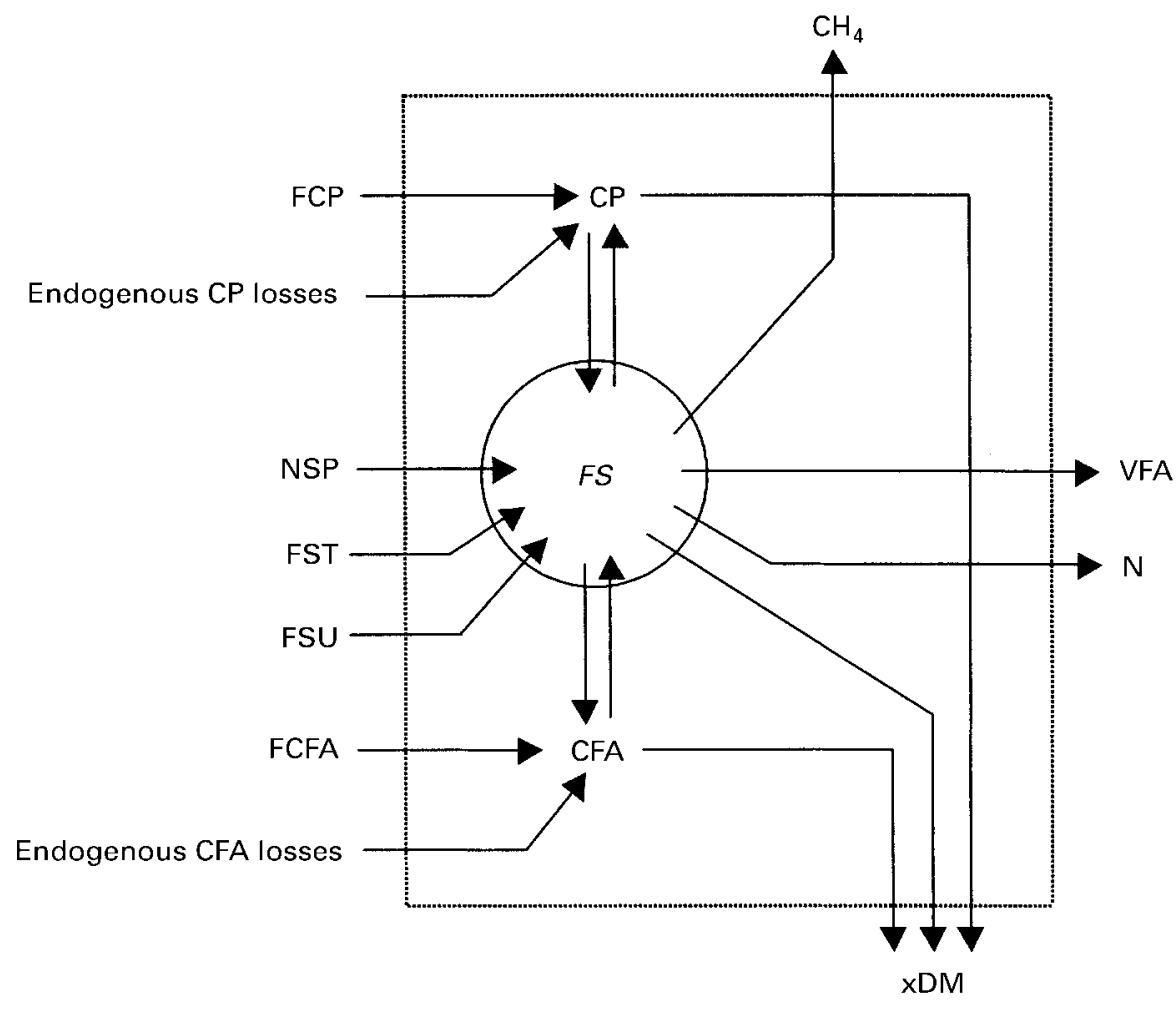

Fig. 2. General representation of fermentation $F$. Inputs are NSP, fermentable starch (FST), sugar (FSU), crude protein (FCP), and crude fat (FCFA), and endogenous CP and CFA gut losses. Exchanges between these and the microbial ecosystem release heat, methane, faecal material (xDM), $\mathrm{N}$ for urinary excretion, and absorbed volatile fatty acids (VFA). A simplified model can be adopted for monogastric animals, by representing only the energy content of the fermentable substrate (FS), and converting this to absorbed VFA via an energy transformation and fixed fermentation efficiency to represent energy lost as heat and with methane. 
assumed that all of the fNSP intake is fermented (FNSP) and is included in FS. Contributions to FS from fermentable ST and SU are calculated by the difference between faecal and ileal digestible fractions: $\mathrm{FST}=\mathrm{FST}-\mathrm{iST}$, and $\mathrm{FSU}=$ fSU - iSU.

FCP is calculated as the difference between apparent fCP and true $\mathrm{iCP}$ intake, plus the ileal endogenous gut losses not re-absorbed at the terminal ileum $(\mathrm{eCP})$, i.e. $\mathrm{FCP}=$ fCP $-\mathrm{iCP}+\mathrm{eCP}$. Net CP synthesis may occur at a high rate during fermentation, for example as much as $50-60 \mathrm{~g}$ bacterial protein/kg fNSP in pigs (Bakker, 1996). Moreover, when energy is limiting, microbial CP may be used to generate FA (Jorgenson et al. 1996). Neither of these pathways for synthesis or degradation of microbial protein is explicitly represented. A non-negative FCP is assumed to be fully de-aminated and converted as a component of FS to VFA. Net synthesis of microbial protein is represented in the simplified process $F$ by reducing the energy content of FS by an amount equivalent to the energy content of the synthesized $\mathrm{CP}$. The $\mathrm{N}$ from fermentation of FCP contributes to urinary $\mathrm{N}$ and cannot be used for protein synthesis.

Similar to the simplified representation of FCP, fermentable fat intake (FCFA) is represented as the difference between apparent faecal and true ileal digestible fat intake, plus ileal endogenous fat losses not reabsorbed at the terminal ileum $(\mathrm{eCFA})$, i.e. $\mathrm{FCFA}=\mathrm{fCFA}-\mathrm{iCFA}+$ eCFA. FCFA production can be attributed to similar sources as those for FCP: dietary, endogenous losses, and bacterial synthesis of FA. Values of FCFA for pigs range between about -4.5 to $+4.5 \mathrm{~g} / \mathrm{kg}$ DM intake (calculated from Noblet et al. 1989; Jorgensen et al. 1993). As for CP, a non-negative FCFA is converted to VFA as a component of FS. Net synthesis of FCFA, i.e. negative FCFA, is represented in the simplified model by a reduction of FS energy by an amount equivalent to the energy content of the synthesized CFA. The lack of accurate input data on ileal and faecal fat digestibilities and endogenous fat losses makes it difficult to parameterize this aspect of CFA digestion in a meaningful way, therefore further simplifications may be appropriate for practical reasons (Birkett \& de Lange, 2001b).

Fermentable substrate is calculated from the separate nutrient contributions as FS $=$ FNSP + FST + FSU + FCP + FCFA. To convert FS to VFA the fermentable energy intake (FE) defined as the energy content of FS, is first calculated including suitable reductions to accommodate negative FCP or FCFA. Stoichiometry of fermentation implies that about $6 \% \mathrm{FE}$ is lost as heat and about $15 \%$ as $\mathrm{CH}_{4}$ (Bakker, 1996; Hungate, 1966), a total energetic loss of about $20 \%$ FE. The exact value will vary, depending, for example, on variation in $\mathrm{CH}_{4}$ production and the composition of the FNSP fraction, an increased content of soluble NSP being associated with higher efficiencies. Since no precise relationship has yet been established, and, in any case, NSP composition of animal diets will vary widely, it is reasonable to assume a fixed average value of say $83 \%$ in converting FE into an equivalent energy flow of VFA, based on reported experimental values between 80 and $90 \%$ (Longland et al. 1988; Zhu et al. 1993; Bakker, 1996 (Table 6.7)). The calculated energy flow in the form of absorbed VFA is then converted, using the heats of combustion, into separate molar flows of individual VFA- acetic $\left(\mathrm{C}_{2}\right)$, propionic $\left(\mathrm{C}_{3}\right)$, butyric $\left(\mathrm{C}_{4}\right)$, and so on, according to which VFA are prevalent in the particular species being represented. For example, for pigs it is sufficient to represent only the absorbed acetic, propionic, and butyric acids heats of combustion for these VFA are given in Table 2 see p. 667. To partition the VFA produced it is assumed that they are present under constant molar proportions. For example, $\mathrm{C}_{2}: \mathrm{C}_{3}: \mathrm{C}_{4}$ molar ratios in the hindgut of pigs are reported to be in the proportions of 70:25:5 (Kirchgeßner \& Müller, 1991); Bakker (1996) reports measured ratios that remain reasonably constant over quite extreme diet compositions. Constant molar VFA proportions is not an unreasonable assumption for the purpose of representing the energetic efficiency of fermentation in monogastric animals, however, in ruminant applications, for which VFA form a larger component of the energy substrate, or for which the precise proportions of absorbed VFA may be important (e.g. dairy cows), a more complex representation of fermentation is likely to be required.

Outputs of the fermentation process are absorbed molar flows of whatever separate VFA are represented.

\section{Intake energy requirements}

The intake process requires energy for ingestion, digestion, and absorption, to support the physical work of processing the nutrients in fDM, and for the biochemical changes which these undergo during digestion, absorption, and transport to sites for metabolic processing. The physical nature of intake as a materials processing operation implies that these energy requirements should be closely related to the mass of material processed, rather than to molar or energy flows. For instance, it is not unreasonable to assume that $1 \mathrm{~g}$ carbohydrate requires the same amount of energy as $1 \mathrm{~g}$ fat intake. Other factors such as fibre effect on water holding capacity and viscosity of the digesta may play a role, but these are ignored. Energy requirements to support the intake process, expressed in terms of ATP requirements, provide the intake calibration parameter ATPd (mol ATP/g fDM), assumed to be linearly related to fDM intake (g/d).

\section{Metabolic process}

The main metabolite flows represented in the metabolic process $(M)$ shown in Fig. 3 are GL, acetyl-CoA (ACA), and ATP. Absorbed iAA, iNSN, iFA, and iNSF are either made available for use as anabolic substrates by the production process, or transformed into metabolites via processes which represent simple catabolic biochemical reactions. All absorbed GL enters the GL metabolite pool directly, all absorbed VFA are catabolized, and the GY associated with $\mathrm{iFA}$ is converted into GL. The AA and NSN from degraded body protein, and FA and GY from degraded body lipid, may enter the free body pools represented in M. ATP outputs are produced as needed to meet the energy requirements of the main nutritional processes. Urinary $\mathrm{N}$ is a waste output, derived from catabolism of AA and NSN, and from non-specific urinary NSN losses. Metabolite flows and the stoichiometry of metabolite biochemical transformations are represented by process $M B$. This includes (Fig. 4) 


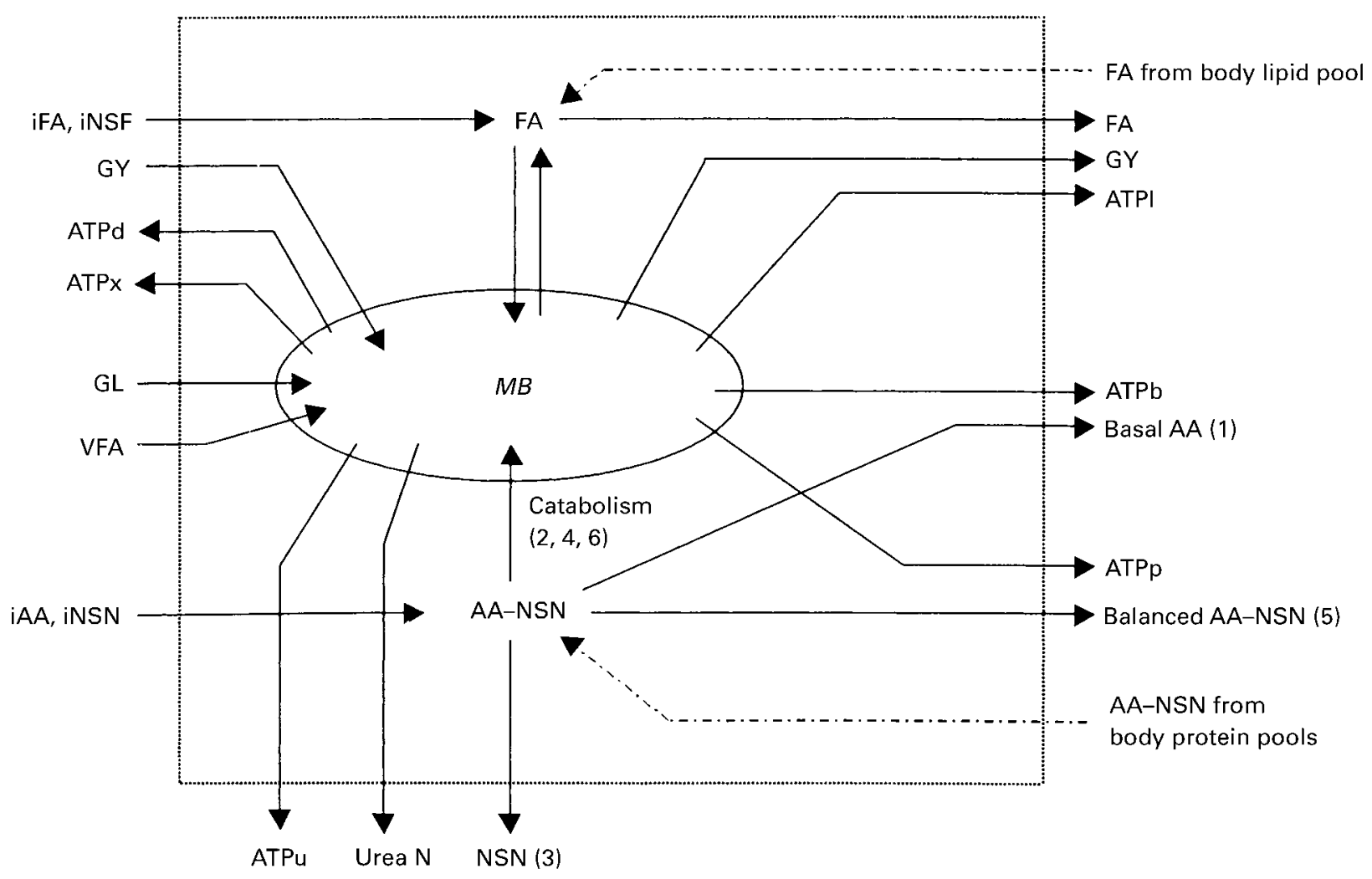

Fig. 3. Metabolic process $M$. Inputs are ileal digestible amino acids (iAA) and non-specific nitrogen (iNSN), glucose (GL), volatile fatty acids (VFA), ileal digestible fatty acids (iFA) and non-specific fat (iNSF), and glycerol (GY). AA-NSN and FA-GY from degraded body protein and lipid pools are returned to the pools in M. In order of priority AA-NSN flows from the free-N pool are: (1) basal AA-NSN requirements to replace physical losses from skin and hair, and basal endogenous gut losses; (2) a minimum level of AA-NSN inevitable catabolism; (3) urinary NSN losses; (4) preferential catabolism in response to energy intake limitation; (5) balanced AA-NSN for body protein synthesis; (6) excess AA-NSN catabolism. Basal ATP requirement (ATPb), and ATP for intake (ATPd), faecal excretion (ATPx), urinary excretion (ATPu), and protein (ATPp) and lipid retention (ATPI) is supplied by M. FA catabolism occurs only if ATPb cannot be supplied otherwise. Balanced FA and GY are outputs for synthesis of body lipid. Metabolite transformations in process $M B$ represent metabolite biochemistry and produce heat. Urea $\mathrm{N}$ from $\mathrm{AA}-\mathrm{NSN}$ catabolism is an output.

catabolic processes for AA, FA, VFA, GL, and ACA (AAc, $F A c, V F A c, G L c$, and $A C A c$ ), and anabolic processes to represent synthesis of the GY and FA (GYs and FAs) required for body lipid synthesis. These processes in $M B$ contribute to the metabolic heat production as a result of biochemical inefficiencies which are represented either explicitly, expressed in terms of specified ATP requirements, or implicitly by a reduction in internal energy of outputs $v$. inputs according to the stoichiometry of the metabolite transformations. A zero net daily flux is demanded between nutrients and the metabolites in $M B$.

\section{Amino acids}

AA and NSN must be provided from the free body pool to replace basal physical losses from skin and hair, and endogenous gut losses. Furthermore, a minimum rate of inevitable catabolism occurs as a consequence of biochemical controls and AA-degrading enzymes which may be down-regulated but always maintain some basal level of activity. For example, Moughan (1999) estimates this for pigs to be between about 15 and $30 \%$ available AA intake. A balanced flow of AA and NSN is output from $M$ to the production process for synthesis of protein to deposit in the various body protein pools. Any AA and NSN in excess of the requirements determined by the constraints of the (genetic) maximum protein retention rate (PdMax), or the supply of the first limiting AA, cannot remain in the free AA and NSN pool for long and must be catabolized (Moughan, 1999). To summarize, fluxes into the body free $\mathrm{N}$-pool (i.e. free AA and NSN) are dietary intake, and the products mobilized from degraded body protein; fluxes out of the pool are, in order of priority, basal requirements to replace physical losses, inevitable catabolism, the requirements for body protein synthesis, and excess catabolism. A net flux of zero in the free- $\mathrm{N}$ pool is balanced on a daily basis by adjusting the level of catabolism of excess AA intake. For practical purposes, the $\mathrm{N}$ flow between the $M$ and production process $(P)$ may be represented simply as the net flow of AA and NSN to production, rather than separate flows in the two directions (see p. 670). Under certain conditions protein retention may be limited by energy intake, i.e. Pd is less than the maximum consistent with AA intake and PdMax. This situation is represented by introducing an additional (preferential) catabolism flow of balanced AA and NSN from the free-N pool, which has the effect of reducing protein retention.

Table 1 shows stoichiometric data for the catabolism of 


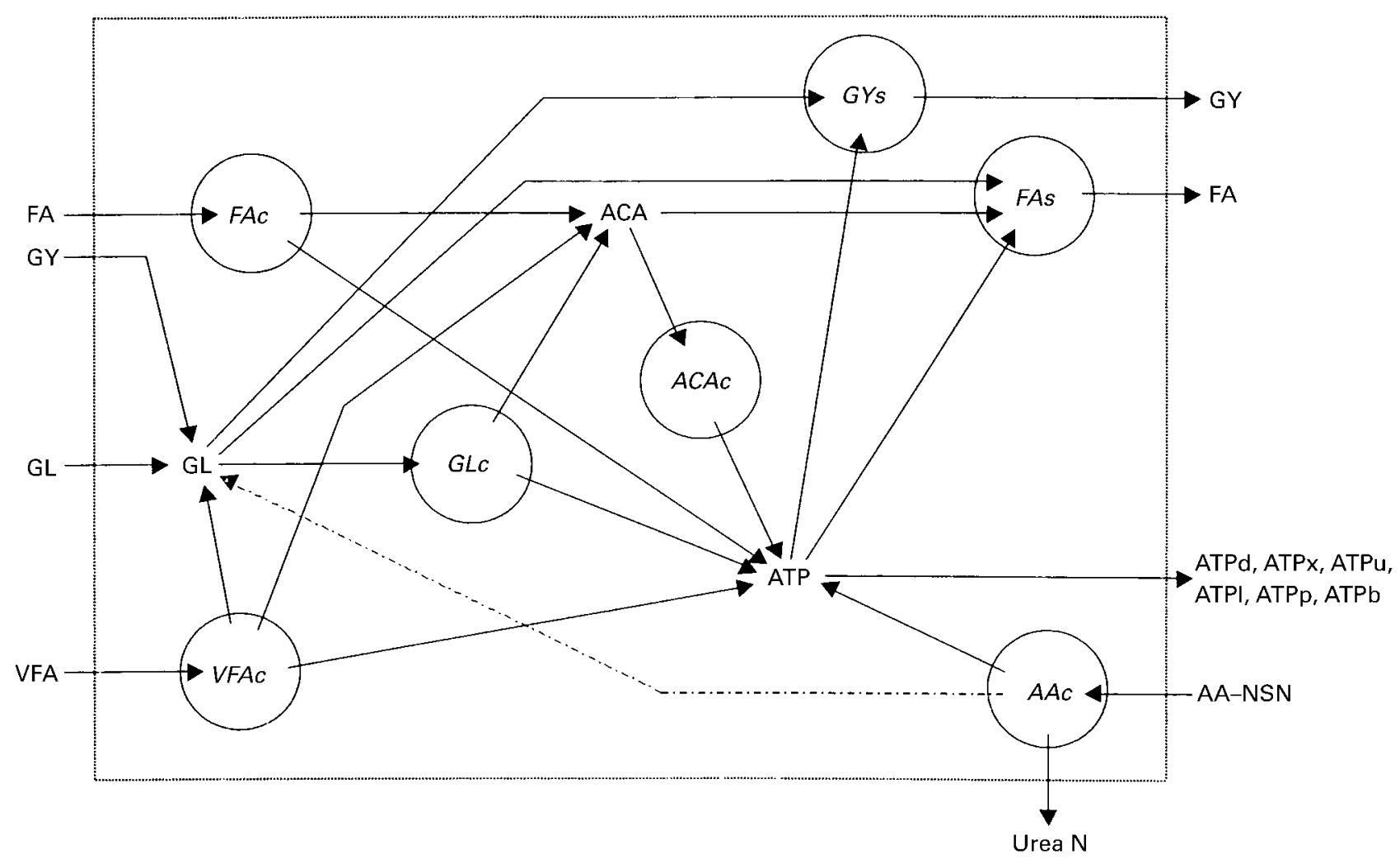

Fig. 4. Metabolite biochemistry process $M B$. Biochemical transformations of absorbed nutrients are modelled by explicit stoichiometry. GL, glucose; VFA, volatile fatty acid; FA, fatty acid; AA, amino acid; NSN, non-specific nitrogen; GY, glycerol. Catabolism is represented for GL $(G L C)$, VFA $(V F A C)$, FA $(F A C)$, and AA-NSN $(A A C)$. An acetyl-CoA (ACA) metabolite flow is represented and ACA catabolism (ACAC). The ATP pool is used to meet the explicit energy requirements for intake (ATPd), urinary excretion (ATPu), faecal excretion (ATPx), protein (ATPp) and lipid retention (ATPI), and basal requirements (ATPb). Process $A A c$, producing urea $\mathrm{N}$ output, is assumed to be oxidation, but gluconeogenesis can be represented if required. Catabolic process FAc only occurs if intake is insufficient to meet ATPb. GY input from fat intake (CFA) is directed to GL pool. GY synthesis (GYs), and FA synthesis (FAs) produce GY and de novo FA for balanced body lipid synthesis. Biochemical inefficiency is represented via stoichiometry. Energy required for basal processes and not explicitly accounted for separately is provided by ATPb. Energy required for all production-related metabolic processes is included in the ATPp and ATPI requirements. Heat production is a consequence of biochemical inefficiency.

Table 1. Stoichiometric data for catabolism of amino acids and non-specific nitrogen

\begin{tabular}{|c|c|c|c|c|c|c|c|}
\hline \multirow[b]{2}{*}{ AA } & \multirow{2}{*}{$\begin{array}{c}\mathrm{MM} \\
(\mathrm{g} / \mathrm{mol})\end{array}$} & \multicolumn{3}{|c|}{ Gluconeogenesis* } & \multicolumn{2}{|c|}{ Oxidation } & \multirow[b]{2}{*}{ UR } \\
\hline & & $\mathrm{GL}$ & ATP & ATP equiv† & ATP $\ddagger$ & ATP§ & \\
\hline NSNף & 106 & 0.42 & $2 \cdot 97$ & $18 \cdot 9$ & $20 \cdot 71$ & & 0.5 \\
\hline Threonine & 101 & 0.5 & 0.5 & 19.5 & 21 & 20.5 & 0.5 \\
\hline Methionine & 131 & 0.5 & 0.5 & 19.5 & 18 & 21.5 & 0.5 \\
\hline Valine & 99 & 0.5 & 11.5 & 30.5 & 30 & 31.5 & 0.5 \\
\hline Leucine & 113 & NA & NA & NA & 40 & $39 \cdot 5$ & 0.5 \\
\hline Isoleucine & 113 & 0.5 & 20.5 & 39.5 & 41 & $40 \cdot 5$ & 0.5 \\
\hline Lysine & 128 & NA & NA & NA & 35 & 36 & 0.5 \\
\hline Phenylalanine & 147 & 0.5 & 19 & 38 & 39 & 37.5 & 0.5 \\
\hline Trytophan & 186 & 0.5 & 21 & 40 & NV & 42 & 1 \\
\hline Histidine & 137 & 0.5 & $2 \cdot 5$ & 21.5 & 21 & $22 \cdot 5$ & 1.5 \\
\hline Arginine & 156 & 0.5 & 8 & 27 & 29 & 28 & 2 \\
\hline Cysteine & 103 & 0.3 & 0 & $5 \cdot 7$ & 13 & $12 \cdot 5$ & 0.5 \\
\hline Tyrosine & 163 & 0.5 & 21.5 & 40.5 & 42 & 41.5 & 0.5 \\
\hline
\end{tabular}

$\mathrm{AA}$, amino acid; MM, molecular mass of free AA; GL, glucose; equiv, equivalent; UR, urea; NSN, non-specific nitrogen; NA, not applicable; NV, no value given.

*From Schulz (1978).

† Values calculated from ATP yield plus 38 ATP/mol GL oxidation.

† From Krebs (1964) and Armstrong (1969).

$\S$ From Schulz (1978).

$\|$ Values are net mol UR/mol AA catabolized.

I Values are estimated (see p. 667). 
twelve AA via two main catabolic pathways, direct oxidation and gluconeogenesis. Urea yield is determined by the molar concentration of $\mathrm{N}$ in each AA and is the same for either pathway. ATP and GL yields are given for gluconeogenesis from Schulz (1978), in which it is assumed that the AA are converted to $\mathrm{CO}_{2}, \mathrm{H}_{2} \mathrm{O}$, urea and GL. The 'equivalent ATP yield' shown for gluconeogenesis has been calculated as the direct ATP yield plus the ATP which would be obtained by complete oxidation of the produced GL at the rate of $38 \mathrm{~mol} \mathrm{ATP/mol} \mathrm{GL}$. Data for ATP yield from AA oxidation to $\mathrm{CO}_{2}, \mathrm{H}_{2} \mathrm{O}$, urea and ATP are given from two sources (Krebs, 1964; Armstrong, 1969; Schulz, 1978). There are some small differences in ATP yield between these but the discrepancies are not significant. Net ATP yields are given, and make allowance for the ATP required for synthesis of urea, $2 \mathrm{~mol} \mathrm{ATP} / \mathrm{mol} \mathrm{N}$ (Armstrong, 1969). Values for the stoichiometry of NSN catabolism are calculated from corresponding data for nonessential AA in the weighted proportions they are present in a typical $160 \mathrm{~g} \mathrm{CP} / \mathrm{kg}$ maize-soyabean meal diet. The urea (or with the most generality, also uric acid) resulting from AA and NSN catabolism is a waste output of $M$.

It is difficult to determine the relationship between specific metabolic conditions and the extent to which the catabolic pathways gluconeogenesis or oxidation are followed for a particular AA (only leucine and lysine are exclusively ketogenic). Lindsay (1976) concludes that the major proportion of AA catabolism for monogastric animals (about 90\%) proceeds via oxidation. Gill et al. (1984) assume an oxidation ratio of $80 \%$ in their model of a young sheep, consistent with the general observation that gluconeogenesis occurs at a higher rate for ruminant animals (Lehninger et al. 1993). However, in terms of the effect on energetic efficiency, the choice of catabolic pathway for AA is essentially irrelevant, as can be seen by comparing the stoichiometry and overall ATP yields in Table 1. This observation is also confirmed by the very small differences in retained energy predicted by comparative model simulations forcing exclusively one or the other of the two catabolic pathways for AA. Therefore, provided GL is non-limiting, it can be assumed with no loss of generality at the whole animal level that all AA catabolism proceeds via oxidation.

\section{Volatile fatty acids}

Absorbed VFA, acetic, propionic, butyric acid, and so on, are metabolic inputs that contribute to the generation of ATP and GL. Faecal excretion of VFA is generally very low, for instance, in pigs not more than 1-2\% energy infused (Kirchgeßner \& Müller, 1991). Therefore it is reasonable to assume a complete absorption of the VFA derived from fermentation. All absorbed VFA are assumed to be catabolized via the stoichiometry summarized in Table 2. Acetic acid and butyric acid are converted to ACA. The main pathway for propionic acid, conversion to GL in the liver (McDonald et al. 1995), is assumed in the model (the minor pathway from propionic acid directly to ACA is ignored).
Table 2. Molar weights and heats of combustion for some volatile fatty acids, and stoichiometric data for volatile fatty acids catabolism*

\begin{tabular}{cccclc}
\hline & $\mathrm{MW} \mathrm{g} / \mathrm{mol}$ & $\mathrm{Hc} \mathrm{kJ} / \mathrm{mol}$ & $\mathrm{ATP} \dagger$ & $\mathrm{GL}$ & $\mathrm{ACA}$ \\
\hline $\mathrm{C}_{2}$ & 60 & 876 & -2 & 0 & 1 \\
$\mathrm{C}_{3}$ & 74 & 1536 & -2 & 0.5 & 0 \\
$\mathrm{C}_{4}$ & 88 & 2193 & 3 & 0 & 2 \\
\hline
\end{tabular}

Mw, molar weight; Hc, heat of combustion; GL, glucose; ACA, acetyl-CoA.

${ }^{*}$ From Armstrong (1969) and McDonald et al. (1995).

$\dagger$ Negative value denotes an ATP requirement.

\section{Fatty acids}

Absorbed dietary iFA are either directly incorporated into body lipid, or catabolized via $\beta$-oxidation to ACA and ATP. The choice between these two pathways affects both the energetic efficiency of utilizing dietary fat for production, and the FA composition of the retained body lipid. For a particular species it may be possible to neglect fat catabolism altogether under conditions when available non-fat energy intake is above basal requirements, as reported in Chudy \& Schiemann (1967) for rats. In general, dietary FA are absorbed by monogastric animals largely unchanged, as reflected by the resemblance between the FA composition of adipose tissue and that of the diet fed (Leat et al. 1964; Koch et al. 1968; Mills et al. 1976). For pigs, Metz et al. (1977) report a moderate level of inevitable FA catabolism, between 15 and $45 \%$, and decreasing with an increased intake level and diet fat content. Based on the very high energetic efficiency observed for fat retention, Boyd \& McCracken (1979) conclude that the rate of de novo fat synthesis is low in pigs fed high-fat diets. Using data from indirect calorimetry to estimate substrate oxidation in 30$90 \mathrm{~kg}$ pigs, Chwalibog et al. (1997) determined no significant oxidation of fat despite large variation in digestible fat intakes from $0-8 \mathrm{~g} / \mathrm{kg}^{0.75}$. These results suggest that the rate of catabolism of dietary FA for pigs is generally low, provided basal energy requirements can be met from other nutrient sources and FA retention in body lipid exceeds FA intake. Similary to AA metabolism, FA supplied in excess of FA retained are catabolized.

Stoichiometry for FA catabolism depends on the number of $\mathrm{C}(2 n)$ and the number of double bonds (p) in a particular FA. The ACA and ATP yields per mol FA are $n$ mol and $-2+5(n-1)-2 \mathrm{p}$ mol, respectively (Lehninger et al. 1993). Stoichiometric data for FA catabolism are summarized in Table 3. For simplicity iNSF is converted to an equivalent iFA molar flow, for instance using 18:2. GY intake derived by association with iFA intake is assumed to be converted directly to GL (with no explicit energy cost) at the rate of $1 \mathrm{~mol} \mathrm{GL} / 2 \mathrm{~mol} \mathrm{GY}$.

\section{Glucose and Acetyl-CoA}

Glucose can either be completely catabolized as an energy substrate to generate ATP, or it can serve as a material substrate for de novo FA synthesis, providing GY and the reduced coenzyme NADPH directly, or ACA as an intermediate product of catabolism. With regard to overall energetics, the conversion of GL to GY can reasonably be ignored since body GY stores are small. The substantial 
Table 3. Stoichiometric data for fatty acids and glycerol*

\begin{tabular}{lcccc}
\hline FA† & $\mathrm{MM}^{\mathrm{F}}(\mathrm{g} / \mathrm{mol})$ & $\mathrm{MM}^{\top}(\mathrm{g} / \mathrm{mol})$ & ACA $\neq$ & ATP \\
\hline 10:0§ & 172 & 554 & 5 & 18 \\
Lauric (12:0) & 200 & 638 & 6 & 23 \\
Myristic (14:0) & 228 & 722 & 7 & 28 \\
Palmitic (16:0) & 256 & 806 & 8 & 33 \\
Palmitoleic (16:1) & 254 & 800 & 8 & 31 \\
Stearic (18:0) & 284 & 890 & 9 & 38 \\
Oleic (18:1) & 282 & 884 & 9 & 36 \\
Linoleic (18:2) & 280 & 878 & 9 & 34 \\
Linolenic (18:3) & 278 & 872 & 9 & 32 \\
20:0ll & 312 & 974 & 10 & 43 \\
\hline
\end{tabular}

$\mathrm{FA}$, fatty acid; $\mathrm{MM}^{\mathrm{F}}$, molecular mass of $\mathrm{FA} ; \mathrm{MM}^{\top}$, molecular mass of triacylglycerol; ACA, acetyl-CoA.

* From Lehninger et al. (1993).

Designated by the number of $\mathrm{C}$ atoms in the chain followed by the number of double bonds.

$\ddagger$ Denotes yields for $\beta$-oxidation of $F A$.

$\S$ Value used to represent all FA with less than twelve $C$.

II Value used to represent all FA with more than eighteen C.

amount of de novo lipid synthesis which often occurs in producing animals implies that the explicit representation of the intermediary ACA metabolite pool in the nutritional process model is essential, if a proper account is to be made of the metabolic use of nutrients. Moreover, in monogastric animals the typically low rates of both VFA production and FA catabolism imply that only small quantities of ACA will be generated from these sources. Complete oxidation of $1 \mathrm{~mol} \mathrm{GL}$ via the tricarboxylic-acid cycle produces $\mathrm{CO}_{2}$, $\mathrm{H}_{2} \mathrm{O}$, and a yield of $38 \mathrm{~mol}$ ATP (Armstrong, 1969). Alternatively, ACA and ATP may also be generated at an intermediate step in the tricarboxylic-acid cycle (Table 4). Therefore, in order to ensure that ACA is non-limiting, GL oxidation is represented by the two catabolic processes $G L c$ and ACAC (Table 4).

GL may also serve as a substrate for synthesis of the substantial quantitities of NADPH required for de novo FA synthesis, with $12 \mathrm{~mol}$ NADPH being derived from $1 \mathrm{~mol}$ GL at the expense of 1 mol ATP for activation (Armstrong, 1969). The process representing de novo FA synthesis $(F A s)$ is based on stoichiometry (Table 5) requiring GL to provide NADPH, ACA for C skeletons, and ATP (Lehninger et al. 1993). Each component in the FA chain requires $1 \mathrm{ACA}$; each coupling of $\mathrm{ACA}$ into the $\mathrm{FA}$ chain requires $1 \mathrm{~mol}$ ATP and 2 mol NADPH; an additional 1 (or 2) mol NADPH is required for the double (or triple) bond in an unsaturated FA; 1 mol ATP is required to activate each mol GL in the hexose monophosphate shunt that produces

Table 4. Stoichiometric data for glucose and acetyl-CoA pathways*

\begin{tabular}{lcccc}
\hline & \multicolumn{4}{c}{ Outputs (mol) } \\
\cline { 2 - 5 } Input (mol) & ATP† & ACA & GY & NADPH \\
\hline GL & 14 & 2 & & \\
ACA & 12 & & 2 & \\
GL & -8 & & & 12 \\
GL & -1 & &
\end{tabular}

ACA, acetyl-CoA; GY, glycerol; GL, glucose.

*From Armstrong (1969) and Frayn et al. (1995).

†Negative value denotes a net ATP requirement.
Table 5. Stoichiometric requirements for synthesis of $1 \mathrm{~mol}$ fatty acid $^{*}$

\begin{tabular}{lccc}
\hline & \multicolumn{3}{c}{ FA synthesis } \\
\cline { 2 - 4 } & ATP & ACA & GL \\
\hline $18: 1$ & 9.42 & 9 & 1.42 \\
$18: 0$ & 9.33 & 9 & 1.33 \\
$16: 0$ & 8.17 & 8 & 1.17 \\
\hline
\end{tabular}

FA, fatty acid; ACA, acetyl-CoA; GL, glucose.

${ }^{*}$ From Lehninger et al. (1993).

NADPH. Processes may be included to represent the stoichiometry of synthesizing various different FA, but this would also require rules for determining the proportion in which each of these is produced. Such detail would be desirable if the FA content of the deposited lipid in the carcass is to be predicted by the model. However, if the main purpose of the model is to predict the energetic efficiency of nutrient utilization, the choice of synthesized FA becomes less significant and it may be reasonably assumed that de novo lipid is built from a single synthesized FA source. For example, oleic acid (18:1) would be a reasonable choice for pigs (Pettigrew et al. 1992; Gerrits, 1996), in which it accounts for as much as $50 \% \mathrm{FA}$ in white adipose tissue (Enser, 1984). GL may also be converted into GY at a cost of $4 \mathrm{~mol} \mathrm{ATP/mol} \mathrm{GY,} 1 \mathrm{~mol} \mathrm{GL}$ producing $0.5 \mathrm{~mol}$ GY (Frayn et al. 1995) which is made available to the production process for use in the synthesis of triacylglycerol.

\section{Faecal and urinary excretion processes}

The faecal excretion process $(f X)$ represents the ingestion of non-digestible and endogenous material (xDM), its processing, and the excretion of faeces (Fig. 5). This process requires support energy which, as for the processing of $\mathrm{fDM}$, is assumed to be linearly related to the mass of $\mathrm{xDM}$ and is expressed as an ATP requirement determined by the faecal excretion calibration parameter ATPx (mol ATP/g $\mathrm{xDM})$. Most of the energetic requirements for processing $\mathrm{xDM}$ will also apply to fDM, therefore it can be expected that the value of ATPX determined in a reasonable calibration procedure should not exceed that of ATPd.

The urinary excretion process $(u X)$ represents the synthesis of urea (or uric acid), and the urinary excretion of all non-metabolizable and endogenous materials (Fig. 5). These include non-specific losses, i.e. minimum urinary NSN losses and non-nitrogenous components in urine, $\mathrm{N}$ from AA catabolism, and $\mathrm{N}$ from fermented $\mathrm{CP}$. The process requires support energy to reflect the stoichiometric ATP requirements of urea synthesis, and the indirect energy requirements of all metabolic processes associated wih urinary excretion. These combined energy requirements are expressed as the ATP requirement ATPu. Based on the stoichiometric ATP requirement for synthesizing urea at $2 \mathrm{~mol} \mathrm{ATP} / \mathrm{mol}$ urea $\mathrm{N}$, an equivalent metabolizable energy cost of about $11 \mathrm{~kJ} / \mathrm{g}$ urea $\mathrm{N}$ may be estimated (using an estimated metabolizable energy equivalent of $77 \mathrm{~kJ} / \mathrm{mol}$ ATP). Estimated actual metabolizable energy cost 


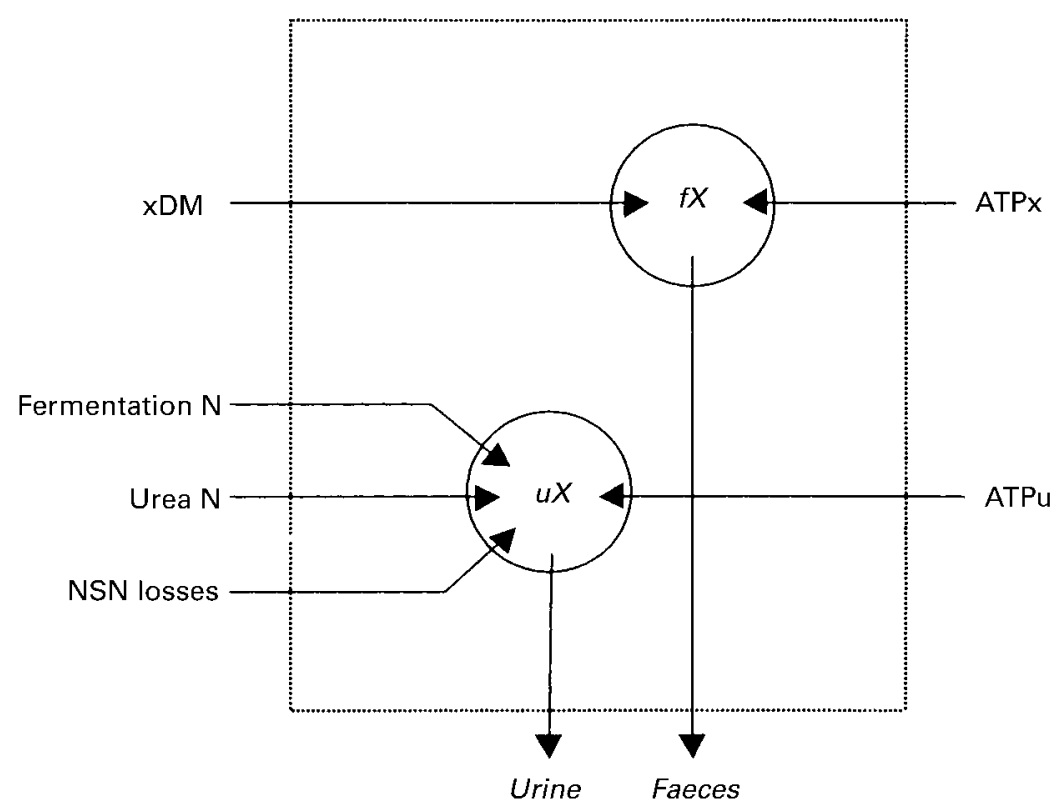

Fig. 5. Excretion process. Faecal excretion process $(f X)$ represents ingestion, processing and excretion of non-digestible material as faeces, with energy requirement ATPx. Urinary excretion process $(u X)$ represents the metabolic processes associated with synthesis of urea, processing of fermentation $\mathrm{N}$ and non-specific nitrogen (NSN) losses, and the synthesis and excretion of urine, with overall energy requirement $\mathrm{ATPu}$.

associated with urinary excretion is estimated consistently to be between about 29 and $31 \mathrm{~kJ} / \mathrm{g}$ urinary $\mathrm{N}$ (Buttery \& Boorman, 1976; Whittemore, 1983, 1997; Blaxter, 1989; Emmans, 1994; ). Thus, the energy requirement for urinary excretion can be closely associated with the quantity of urinary $\mathrm{N}$ excreted, and expressed as an ATP requirement estimated to be about three times the stoichiometric ATP requirement for synthesizing urea $\mathrm{N}$. Energy requirements for $u X$ are related to the loss of non-nitrogenous components in urine, various transport and metabolic processes that occur in the urea cycle, and other metabolic processes which are associated with urinary excretion. This connection is useful in that it allows some of the effects of variation in body protein turnover rate to be accommodated through the energy requirements related to urinary $\mathrm{N}$ excretion.

\section{Production process}

The production process (Fig. 6) represents the conversion of balanced anabolic substrates (AA and NSN, FA and GY) into synthesized body protein and lipid, and the retention of these in the body pools. The mobilization of the FA, GY, AA and NSN constituents of body protein and lipid, and the return of these to free body pools in $M$, is also represented in the most general model of the production process for growing animals.

\section{Protein retention}

A material flow diagram of the protein retention process shows (Fig. 6) body protein synthesized from balanced AA and NSN in process $P s$, and degraded in process $P g$ to AA and NSN which are returned to the free-N pool in $M$. The balance in which AA are required for net protein deposited (Pd) may be defined by the composition of the body protein pool(s) for which it is being synthesized, either whole-body protein, or, in a more sophisticated model, in terms of defined body protein pools. This approach to modelling protein retention represents explicitly all the relevant AA and NSN flows between the free pool and body protein pools. Pd is the difference of separate rates of $P s$ and $P g$. The relationship between the rate of $P s$ and $\mathrm{Pd}$ is highly variable, for example synthesis ranging from 2-3 times Pd for $30 \mathrm{~kg}$ pigs, and increasing to 10 times for $90 \mathrm{~kg}$ pigs (Reeds et al. 1980). Even when Pd is zero, both $P s$ and $P g$ can continue to operate at high rates, for example over $200 \mathrm{~g} / \mathrm{d}(34 \mathrm{~g} \mathrm{~N} / \mathrm{d})$ being estimated for $30 \mathrm{~kg}$ pigs based on extrapolation of the relationship between protein synthesis and $\mathrm{N}$ retention (Reeds et al. 1980; Fig 4). Explicit representation of protein turnover (i.e. separate rates of $P s$ and $P g$ ) requires independent estimates for the rates and energy requirements for these two processes, and an understanding of the factors which influence them. This is hampered by inadequate methodology to measure synthesis and degradation accurately under varying metabolic states and environmental conditions (Reeds, 1992). Furthermore the complex regulatory controls governing rates of synthesis and degradation appear to act independently, and unequivocal links between these and processes at the whole animal level have not yet been established (Moughan, 1999; Knap, 2000). For example, an increase in Pd resulting from increased dietary protein intake is a consequence of an increase in the rate of $P s$ and a smaller increase in rate of $P g$ (Reeds \& Fuller, 1983; Fuller et al. 1987). On the other hand, an increase in non-protein energy increases $P d$ as the consequence of a small increase in the rate of $P S$ and a small 


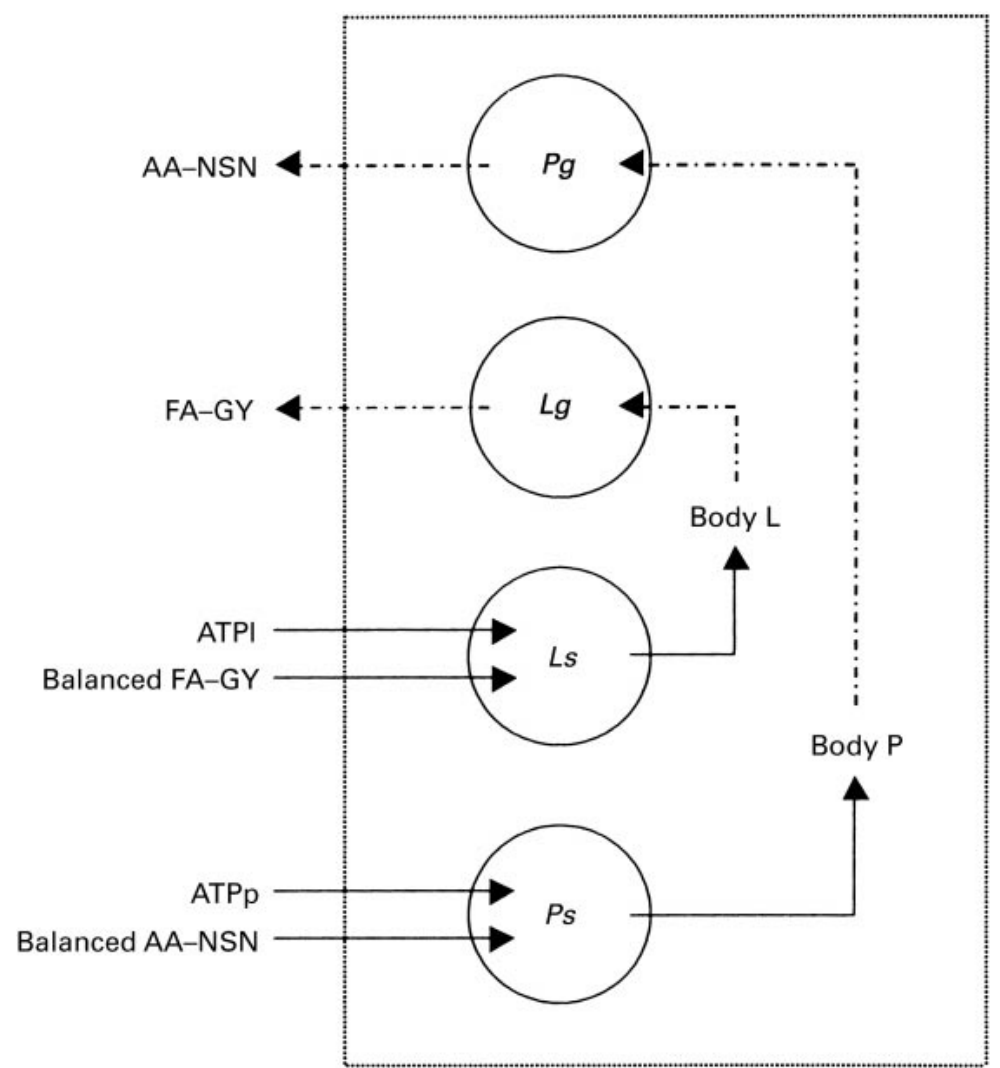

Fig. 6. Production process $P$. Balanced glycerol (GY) and fatty acids (FA) from de novo and dietary sources are transformed in the lipid synthesis process $(L s)$ to triacylglycerols retained in body lipid pool $L$, lipid; $P$, protein. Balanced amino acids (AA) and non-specific nitrogen (NSN) are transformed to retained body protein in the protein synthesis process $(P S)$. Degradation and mobilization of FA-GY and AA-NSN are represented by processes $\mathrm{Lg}$ and $P g$. Simplified model assumes synthesis at the rate of the net lipid (Ld) and protein $(\mathrm{Pd})$ retained, with no degradation. Energy requirements associated with Ld and Pd are provided by ATPI and ATPp, supporting all metabolic processes which are incrementally associated with incremental lipid and protein retention.

decrease in rate of $P g$ (Reeds \& Fuller, 1983). Improved dietary protein quality, achieved by raising the level of the first-limiting AA increases Pd with little change to the rate of $P s$ and a significant decrease in that of $P g$ (Fuller $e t$ al. 1987). Finally, we have recently demonstrated that a reduction in diet digestibility increases protein turnover, i.e. rates of both $P s$ and $P g$, in gut protein (Nyachoti et al. 2000), with likely little change in Pd.

The significant problems associated with adequately representing $P s$ and $P g$ separately suggest the use of a simplified representation in which only $\mathrm{Pd}$ is explicitly represented (Fig. 6), i.e. the rate of $P s$ is exactly Pd. This requires the substrate materials to flow only in the direction from $M$ to $P$, representing the net balanced AA and NSN required to support $\mathrm{Pd}$. The energy requirements associated with $\mathrm{Pd}$, and consequently energetic efficiency, cannot be completely explained simply by considering the whole body rates of $P s$ and $P g$ that determine net protein retention. Reeds et al. (1980) demonstrate for pigs that the incremental dietary energy for Pd must also be due significantly to increases in other energy-demanding metabolic processes which are associated with an increase in $\mathrm{Pd}$, such as the activity of $\mathrm{Na}^{+} / \mathrm{K}^{+}$pumps. In the simplified model, the energy requirements to support Pd are determined by: (1) an incremental requirement which can be associated directly with an increment in the rate of Pd, expressed as an ATP requirement (ATPp), the mol ATP required to support an increment in $P d$ of $1 \mathrm{~g} / \mathrm{d}$; (2) a residual requirement which is a function only of the animal's physical state, independent of Pd and all other processes explicitly represented in the model. The latter residual energy requirement will be included in the basal ATP requirement $(\mathrm{ATPb})$ discussed later (basal process $B$ ).

The protein retention calibration parameter ATPp includes the energy requirement to support typical increments in rates of protein synthesis and turnover that result in the increment in $\mathrm{Pd}$, plus increments in all metabolic processes which can be associated directly with the protein retention process and are not explicitly included elsewhere in the model, i.e. not included in the energy requirements for intake, and faecal and urinary excretion. Since ATPp has a fixed relationship to Pd, it cannot incorporate the variation in energetic requirements corresponding to different levels of protein turnover at the same 
net rate of retention. However, to some extent, the energetic consequences of this variation are implicitly represented in this nutritional process model in terms of the parameters ATPd, ATPx, and ATPu: (1) an increase in Pd related to increased CP intake, will also be associated with increased urinary excretion, and consequently increased energy requirements associated with $\mathrm{ATPu}$. The extent of this increase will depend on how well-balanced the CP intake is, thereby implicitly representing variation in the relative rates of $P s$ and $P g$; (2) a poorly digestible CP increment will be associated with an additional increase in the energy requirements expressed by ATPx; (3) increased intake of non-protein energy or first-limiting AA increases Pd while reducing the rate of $P g$, the latter effect being associated with a reduced $\mathrm{uN}$ excretion, and therefore a reduced energy requirement determined by ATPu. Finally; (4) the increased energy requirement as a consequence of increased gut turnover rate associated with a decrease in digestibility of nutrient intake, will be represented implicitly in the increased energy requirement for processing $\mathrm{xDM}$, expressed in terms of the parameter ATPX. These observations imply that the energetic consequences of variation in protein turnover rate in relation to $\mathrm{Pd}$ are (at least partially) taken into account implicitly by changes in energy requirements associated with intake, and faecal and urinary excretion.

\section{Lipid retention}

The material flow diagram for the lipid retention process (Fig. 6) is similar to that for protein retention. Process $L s$ represents synthesis of body lipid from balanced GY and FA derived from either de novo or dietary sources; process $L g$ represents degradation of body lipid to the constituent FA and GY, which are returned to the free pools in $M$. The net lipid retained $(\mathrm{Ld})$ depends on the separate rates of $L s$ and $L g$. Mobilization of body fat probably occurs at a low rate for animals fed above their basal energy requirements in a thermoneutral environment (Metz et al. 1977). Therefore, for non-extreme intake and environmental conditions $L g$ can be neglected, in which case Ld is identical to the rate of Ls.

Despite small quantities of structural phospholipids present in all tissues, and some constant presence of mono- and diacylglycerols as intermediates in lipid metabolism, the predominant neutral lipids in adipose tissue are triacylglycerols (Frayn et al. 1995). Although some dietary FA may be altered, for instance by chain elongation, it is assumed for simplicity that these FA are made available for synthesis of triacylglycerol without structural changes. It is therefore not unreasonable to assume de novo lipid consists entirely of triacylglycerol. To synthesize $1 \mathrm{~mol}$ triacylglycerol from $3 \mathrm{~mol} \mathrm{FA}$ and $1 \mathrm{~mol}$ GY requires 2 mol ATP for uptake of each mol FA, a total of $6 \mathrm{~mol}$ ATP/mol triacylglycerol (Frayn et al. 1995); incorporation of the triacylglycerol into body stores does not require energy.

In response to a specified net rate of protein retention, excess metabolites in the pools in $M$ are directed to FA and GY synthesis in the balanced amounts required for incorporation of triacylglycerol in the body pool. Thus Ld is the sink resulting from the algebraic balancing to zero of net daily flux in each of the three metabolite pools ATP, GL, and ACA. The level of de novo lipid synthesized is therefore dependent on the size of these metabolite pools, the stoichiometric relationships represented, and the associated energy requirements for lipid retention. It can be shown algebraically that the separate representation of the ACA flow, and the alternative substrate pathway represented by ACA catabolism, is essential for obtaining a unique solution in the balancing of these pool flows to zero.

The ATP requirements for Ld expressed in terms of the lipid retention calibration parameter ATPl (mol ATP/mol Ld), include for simplicity the (stoichiometric) ATP requirement of $6 \mathrm{~mol} \mathrm{ATP} / \mathrm{mol}$ triacylglycerol to activate the 3 mol FA. Additional ATP over that required for FA activation relates to the energy requirements of all the metabolic processes that are associated with an increase in Ld. The same calibration parameter ATPl applies to lipid retention from either de novo or dietary sources. The residual energy requirement associated with lipid retention but independent of $\mathrm{Ld}$ is assumed to be a function only of the animal's physical state and included in the basal ATP requirement discussed next.

\section{Basal processes}

Basal ATP requirement represents the residual basal free energy expenditure (BE), i.e. that which cannot be associated with feed intake, urinary or faecal excretion, or lipid and protein retention. Consequently, a close connection can be expected with an animal's physical state, independent of its metabolic status and dietary intake, with some adjustment for animal (geno)type, activity and environmental factors. The energy requirements for the various metabolic and physiological processes that contribute to $\mathrm{BE}$ are not separately determined. The main contributors to $\mathrm{BE}$ are protein turnover independent of intake and production level (see p. 669), primarily that required to maintain a minimum visceral size, the associated activity of $\mathrm{Na}^{+} / \mathrm{K}^{+}$pumps, and maintenance of basal metabolism and physiological functions (Milligan \& Summers, 1986; Gill et al. 1989; Yen, 1997; Birkett \& de Lange, 2001a). It is therefore not unreasonable to assume that the basal ATP requirement is related to body protein mass and define the calibration parameter $\mathrm{ATPb}$ as mol ATP required/ $/ \mathrm{kg}$ body protein.

Basal ATP may be supplied (with varying efficiencies) from metabolite sources derived from nutrient intake or from catabolism of body tissues; since it is a free energy requirement at the metabolic level, the value is independent of the source. BE is considerably smaller than the basal heat production at zero energy balance, i.e. the energy intake required to supply BE from dietary nutrients (MEm), which includes heat increments due to the following sources: intake of digestible nutrients (ATPd); processing of associated non-digestible material (ATPx); $\mathrm{N}$ excretion pertaining to the particular state of zero energy retention at which MEm is determined (ATPu); support of the particular non-zero protein accretion rate (ATPp); and a (variable) allowance for the biochemical inefficiency of generating metabolites from absorbed nutrients. In growing pigs the 
free energy content of the basal ATP requirement is typically about one third of dietary basal heat production (Birkett \& de Lange, 2001b). BE may also be related to BMR, the equilibrium whole body heat production achieved after a sufficiently long fast (Tess, 1981). Under these conditions, basal ATP is supplied exclusively from catabolism of body lipid and protein stores, with corresponding heat increments above $\mathrm{BE}$ related to: $\mathrm{N}$ excretion, which continues to occur in a state of zero energy intake, since some $20 \%$ of the energy requirements are typically derived through catabolism (gluconeogenesis) of body protein to maintain an adequate GL pool level (ATPu); and an allowance for the biochemical inefficiency of generating ATP from body nutrient stores.

\section{Discussion}

Different nutrients are utilized by a growing animal with different marginal energetic efficiencies expressed as retained energy:energy intake ratio. Theoretical maximum biochemical efficiencies for lipid synthesis from pure nutrient sources of metabolizable CFA, ST, CP, and VFA can be calculated from stoichiometry to be $98,88,70$ and $75 \%$ respectively (Armstrong, 1969; Noblet \& Henry, 1991). Nutrients supplied in dietary sources from feed ingredients always result in marginal efficiencies for lipid retention from metabolizable energy which are considerably less than these theoretical maximum efficiencies. For example, in pigs typical values for CFA, ST or SU, CP, and VFA, are reported to be 90 (Boyd \& McCracken, 1979), 75 (Schiemann et al. 1962), 55-65 (Kielanowski, 1971), and 50-60\% (Bakker, 1996) respectively. Such biological efficiencies might be called dietary marginal efficiencies to emphasize that energy is being derived by an animal from dietary nutrient sources. Experiments involving pure nutrient infusions into the gut result in intermediate values between biochemical and dietary efficiencies, for instance the reported $60-75 \%$ for lipid retention from pure VFA infusions into the hindgut (Bakker, 1996), because these eliminate most of the intake energy requirements. Reported experimental values for efficiencies of nutrient utilization are variable with regard to these considerations, so they cannot always be directly compared and the range of

Table 6. Marginal energetic efficiency of using digestible nutrients for different metabolic purposes*

Marginal energetic efficiency for generating ATP and depositing lipid

\begin{tabular}{lccccc}
\cline { 3 - 3 } \cline { 5 - 6 } & \multicolumn{2}{c}{ ATP } & & \multicolumn{2}{c}{ Ld } \\
\cline { 2 - 3 } \cline { 5 - 6 } & $\%$ & \% relative to FA & & $\%$ & \% relative to FA \\
\hline FA & 66 & 100 & & 90 & 100 \\
GL & 68 & 103 & & 74 & 82 \\
AA & 58 & 88 & & 53 & 59 \\
CFA & 50 & 76 & & 62 & 69
\end{tabular}

Ld, net lipid retained; FA, fatty acid; GL, glucose; AA, amino acid; CFA, crude fat.

${ }^{*}$ From Black (1995). variation in reported values appears to be larger than it probably really is.

The metabolic use of nutrients also has a significant impact on energetic efficiency. For example, nutrients are used for basal purposes with different efficiencies, and in a different hierarchy, as compared with lipid retention (Table 6). Changes in the relative proportion of basal energy $v$. lipid or protein retention will therefore affect marginal energetic efficiency. Nutrients may also follow different metabolic pathways with different associated efficiencies, for example: direct deposition of dietary FA $v$. catabolism and de novo synthesis; variable faecal excretion as determined by nutrient digestibility; variable urinary excretion as a function of $\mathrm{CP}$ utilization; variable rates of fermentation $v$. enzymatic digestion. Since these metabolic pathways are explicitly represented, the nutritional process model can simultaneously account for the effects of these, as well as nutrient source, on energetic efficiency.

Although no explicit consideration of energy flows is necessary to apply this nutritional process model, it is interesting to consider the implied energy flows generated from simulated nutrient flows and their associated energy densities. This allows the model to function as a mechanistic net energy (NE) model which can take into account both the source and metabolic use of nutrients. BE is, in our view, the representation of net energy for maintenance (NEm), which is generally difficult to define and measure (Birkett $\&$ de Lange, 2001a), defining $\mathrm{NE}=\mathrm{BE}+\mathrm{RE}$, where $\mathrm{RE}$ is retained energy, highly consistent with the classical definition of net energy. Alternatively, model-generated energy flows provide the means to follow a different approach, defining NE as the useful energy an animal derives from feed intake for any purpose, i.e. a measure of the pure biological efficiency of nutrient utilization with only biochemical inefficiency eliminated. Using model simulations NE may be generated as retained energy plus the free energy equivalent of all the explicit ATP generated. The effects of metabolic variation would be much more significant in such an NE system than with the classical definition. In either case, model-generated NE densities can provide a powerful means for quantitatively comparing and ranking diets under defined metabolic conditions.

\section{Conclusions}

A computational framework for a process model of nutrient utilization by animals has been presented. This is applicable to the quantitative representation of body protein and lipid growth in a growing monogastric animal in a wide range of metabolic and nutritional states, and can be adjusted for birds. The model includes defined nutrient and metabolite flows, the interconnections that determine nutrient exchanges between the main processes and with the environment, and an internal structure and parameters to define the input-output response of the main processes. For modelling ruminant animal nutrition, some of the simplifications and assumptions adopted here would not be appropriate, particularly the nutrient transformations used for the intake process. A more detailed explicit representation of fermentation and VFA generation would likely be necessary for a ruminant model, and the choice of 
metabolite flows would have to be modified to reflect those which are important in the ruminant.

By explicitly modelling the main biological and biochemical processes as nutrient transformations, their separate contributions to energetic inefficiency can be estimated. Heat increments that are a consequence of either biological or biochemical processes can be quantified and separated. The differences between response for different monogastric species are related to differences in the parameters that define the biological efficiency. Model response may be adjusted to match observed response for a particular monogastric species by separately adjusting the response of the six main nutritional processes represented. A parameter has been provided for each one of these processes, giving the model five degrees of freedom for marginal response, and one for absolute response. A general calibration procedure for determining the calibration parameters is described in Birkett \& de Lange (2001b), and this is applied to construct a fully parameterized model of nutrient utilization for protein and lipid accretion by growing pigs.

\section{Acknowledgements}

Sincere appreciation is given for the financial support of Agribrands International for the research related to this article. The authors would like to thank Paul Moughan, Martin Verstegen, Patrick Morel and Bruno Marty for their contributions to the development of the concepts. Thanks also to Patrick van Vugt for his background research and his efforts in reviewing metabolic biochemistry.

\section{References}

Armstrong DG (1969) Cell bioenergetics and metabolism. In Handbuch der Tierernaehrung (Band 1) (Handbook of Animal Nutrition), pp. 385-414 [W Lenkheit, K Breirem and E Crasemann, editors]. Hamburg: Paul Parey.

Bakker G (1996) Interaction between carbohydrates and fat in pigs. $\mathrm{PhD}$ Thesis, Wageningen Agricultural University.

Birkett S \& de Lange K (2001a) Limitations of conventional models and a conceptual framework for a nutrient flow representation of energy utilization by animals. British Journal of Nutrition 86, 647-659.

Birkett S \& de Lange K (2001b) Calibration of a nutrient flow model of energy utilization by growing pigs. British Journal of Nutrition 86, 675-689.

Black JL (1995) Modelling energy metabolism in the pig-critical evaluation of a simple reference model. In Modelling Growth in the Pig, EAAP Publication no. 78, pp. 87-102 [PJ Moughan, MWA Verstegen and MI Visser-Reyneveld, editors]. Wageningen: Wageningen Pers.

Blaxter K (1989) Energy Metabolism in Animals and Man. Cambridge: Cambridge University Press.

Boyd J \& McCracken KJ (1979) Effect of dietary fat level and composition on fat and protein retention and efficiency of energy utilization by male castrate pigs between 13 and $40 \mathrm{~kg}$ live weight. In Energy Metabolism, Proceedings of the Eighth Symposium on Energy Metabolism, Cambridge, September 1979, pp. 111-114 [L Mount, editor]. London: Butterworths.

Buttery PJ \& Boorman KN (1976) The energetic efficiency of amino acid metabolism. In Protein Metabolism and Nutrition, EAAP Publication no. 16, pp. 197-206 [DJ Cole, KN Boorman,
PJ Buttery, D Lewis, RJ Neale and H Swan, editors]. London: Butterworths.

Centraal Veevoeder Bureau (1998) Veevoedertabel (Table of Feeding Value of Animal Feed Ingredients). Lelystad: Centraal Veevoeder Bureau.

Chudy A \& Schiemann R (1967) Utilization of dietary fat for maintenance and fat deposition in model studies with rats. In Energy Metabolism of Farm Animals, Proceedings of the Fourth Symposium, Warsaw, Poland, September 1967, EAAP Publication no. 12, pp. 161-168 [KL Blaxter, J Kielanowski and G Thorbek, editors]. Newcastle-upon-Tyne: Oriel Press.

Chwalibog A, Tadson AH \& Thorbek G (1998) Nutrient oxidation and lipogenesis in growing pigs. In Manipulating Pig Production VI, Proceedings of the Sixth Biennial Conference of the Australasian Pig Science Association (APSA), December 1997, pp. 311 [PD Cranwell, editor]. Werribee, Victoria, Australia: APSA.

Dijkstra J, Neal H, Beever D \& France J (1992) Simulation of nutrient digestion absorption, and outflow in the rumen: model description. Journal of Nutrition 122, 2239-2256.

Emmans GC (1994) Effective energy: a concept of energy utilization applied across species. British Journal of Nutrition 71, 801-821.

Enser M (1984) The chemistry, biochemistry and nutritional importance of animal fats. In Fats in Animal Nutrition, pp. 23-51 [J Wiseman, editor]. London: Butterworths.

Frayn K, Humphreys S \& Coppack S (1995) Fuel selection in white adipose tissue. Proceedings of the Nutrition Society 54, 177-189.

Fuller MF, Reeds PJ, Cadenhead A, Seve B \& Preston T (1987) Effects of the amount and quality of dietary protein on nitrogen metabolism and protein turnover of pigs. British Journal of Nutrition 58, 287-300.

Gerrits W (1996) Modelling the growth of preruminant calves. PhD Thesis, Wageningen Agricultural University.

Gill M, France J, Summers M, McBride B \& Milligan L (1989) Simulation of the energy costs associated with protein turnover and $\mathrm{Na}^{+} / \mathrm{K}^{+}$transport in growing lambs. Journal of Nutrition 119, $1287-1299$.

Gill M, Thornley J, Black J, Oldham J \& Beever D (1984) Simulation of the metabolism of absorbed energy-yielding nutrients in young sheep. British Journal of Nutrition 52, 621-649.

Hungate RE (1966) The Rumen and its Microbes. New York, NY: Academic Press.

Jorgensen H, Jakobsen K \& Eggum BO (1993) Determination of endogenous fat and fatty acids at the terminal ileum and on faeces in growing pigs. Acta Agricultuae Scandinavica, Section A, Animal Science 43, 101-106.

Jorgensen H, Zhao X-Q \& Eggum BO (1996) The influence of dietary fibre and environmental temperature on the development of the gastrointestinal tract, digestibility, degree of fermentation in the hind-gut and energy metabolism in pigs. British Journal of Nutrition 75, 365-378.

Kielanowski J (1971) Energy requirements of the growing pig. In Pig Production, Proceedings of the Eighteenth Easter School in Agricultural Science, Nottingham, 1971, pp. 183-201 [DJA Cole, editor]. University Park, PA: Penn State University Press, University Park.

Kirchgeßner M \& Müller HL (1991) Energy utilization via hindgut fermentation in pigs. In Animal Physiology and Animal Nutrition (Supp. to Journal of Animal Physiology and Animal Nutrition), pp. 40-49.

Koch DE, Pearson AM, Magee AM, Hoefer WT \& Schweigert JA (1968) Effect of diet on the fatty acid composition of pork fat. Journal of Animal Science 27, 360.

Knap P (2000) Variation in maintenance requirements of growing 
pigs in relation to body composition. A simulation study. $\mathrm{PhD}$ Thesis, Wageningen Agricultural University.

Krebs H (1964) The metabolic fate of amino acids. In Mammalian Protein Metabolism, chapter 5, vol. 1, pp. 125-176 [H Munro \& JB Allison, editors]. New York, NY: Academic Press.

Leat W, Cuthbertson A, Howard A \& Gresham G (1964) Studies on pigs reared on semi-synthetic diets containing no fat, beef tallow and maize oil: composition of carcass and fatty acid composition of various fat depots. Journal of Agricultural Science 63, 311.

Lehninger A, Nelson D \& Cox M (1993) Principles of Biochemistry, chapter 20. New York, NY: Worth Publishing.

Lindsay DB (1976) Amino acids as sources of energy. In Protein Metabolism and Nutrition, EAAP Publication no. 16, pp. 183-195 [DJ Cole, KN Boorman, PJ Buttery, D Lewis, RJ Neale and H Swan, editors]. London: Butterworths.

Longland A, Low A \& Close W (1988) Contribution of carbohydrate fermentation to energy balance in pigs. In Digestive Physiology in the Pig, Proceedings of the Symposium, Jablonna, Poland, pp. 108-119 [L Buraczewska, S Buraczewska, B Pastuszewska and T Zebrowska, editors]. Jablonna, Poland: Polish Academy of Sciences.

McDonald P, Greenhalgh JFD, Edwards RA \& Morgan CA (1995) Animal Nutrition (Fifth ed.). New York, NY: Longmans.

Metz S, de Wijs M, Dekker R \& Jongbloed A (1977) De inbouw van voervet in lichaamsvet en de afbraaksnelheid van lichaamsvet in het groeiende varken (The incorporation of diet fat in body fat and the rate of degradation of body fat in the growing pig). Rapport 106, IVVO Lelystad, The Netherlands: Instituut vor Veevoedingsonderzoek.

Milligan L \& Summers M (1986) The biological basis of maintenance and its relevance to assessing responses to nutrients. Proceedings of the Nutrition Society 45, 185-193.

Mills S, Cook L, Scott T \& Nestel P (1976) Effect of dietary fat supplementation on the composition and positional distribution of fatty acids in ruminant and porcine glycerides. Lipids 11, 49.

Moughan PJ (1999) Protein metabolism in the growing pig. In $A$ Quantitative Biology of the Pig, pp. 299-332 [I Kyriazakis, editor]. Wallingford: CAB International.

Noblet J, Fortune H, Dubois S \& Henry Y (1989) Nouvelles Bases d'Estimation des Teneurs en Energie Digestible, Metabilisable et Nette des Aliments pour le Porc (New Basis for Estimation of Digestible and Metabolizable Net Energy in Swine Feeds). Saint Gilles: INRA.

Noblet J, Fortune H, Shi XS \& Dubois S (1994) Prediction of net energy values of feeds for growing pigs. Journal of Animal Science 72, 344-354.
Noblet J \& Henry Y (1991) Energy evaluation systems for pig diets. In Manipulating Pig Production III, Proceedings of the Third Biennial Conference of the Australasian Pig Science Assoiation (APSA), Albury, NSW, November 24-27, 1991, pp. 87-110 [ES Batterham, editor]. Victoria: APSA.

Nyachoti M, de Lange CFM, McBride B, Leeson S \& Gabert V (2000) Endogenous gut nitrogen losses in growing pigs are not caused by increased protein synthesis rates in the small intestine. Journal of Nutrition 130, 566-572.

Pettigrew J, Gill M, France J \& Close W (1992) A mathematical integration of energy and amino acid metabolism of lactating sows. Journal of Animal Science 70, 3742-3761.

Reeds PJ (1992) Isotopic estimation of protein synthesis and proteolysis in vivo. In Modern Methods in Protein Nutrition and Metabolism, pp. 249-273 [S Nissen, editor]. New York, NY: Academic Press.

Reeds PJ, Cadenhead A, Fuller MF, Lobley GE \& McDonald JD (1980) Protein turnover in growing pigs. Effects of age and food intake. British Journal of Nutrition 43, 445-455.

Reeds PJ \& Fuller MF (1983) Nutrient intake and protein turnover. Proceedings of the Nutrition Society 42, 463-471.

Schiemann R, Hoffmann L \& Nehring K (1962) Die Verwwertung reiner Nührstoffe 2. Mitteilung (Utilization of pure nutrients 2 . Announcement). Archiv Tierernührung 11, 283-320.

Schultz AR (1978) Simulation of energy metabolism in the singlestomached animal. British Journal of Nutrition 39, 235-254.

Tess M (1981) Simulated effects of genetic change upon life-cycle production efficiency in swine and the effects of body composition upon energy utilization in the growing pig. $\mathrm{PhD}$ Thesis, University of Nebraska.

Whittemore CT (1983) Development of recommended energy and protein allowances for growing pigs. Agricultural Systems 11, $159-186$.

Whittemore CT (1997) An analysis of methods for the utilisation of net energy concepts to improve the accuracy of feed evaluation in diets for pigs. Animal Feed Science Technology 68, 89-99.

Yen J-T (1997) Oxygen consumption and energy flux of porcine splanchnic tissues. In Digestive Physiology in Pigs, Proceedings of the Seventh International Symposium on Digestive Physiology in Pigs, Saint Malo, France, 1997, EAAP Publication no. 88, pp. 260-269 [J-P Laplace, C Février and A Barbeau, editors]. Paris, France: INRA.

Zhu J, Fowler V \& Fuller MF (1993) Assessment of fermentation in growing pigs given unmolassed sugar-beet pulp: a stoichiometric approach. British Journal of Nutrition 69, $511-525$ 